\title{
Title:
}

Accounting for Uncontrolled Variations in Low-Speed Turbine Experiments

\section{Authors details:}

Kathryn R. Evans *

Email: kathryn.evans@cantab.net

John P. Longley

Email: jpl@eng.cam.ac.uk

Whittle Laboratory,

University of Cambridge,

$1 \mathrm{JJ}$ Thomson Avenue,

Cambridge CB3 0DY, UK 


\begin{abstract}
It is common to assume that the performance of low-speed turbines depend only on the flow coefficient and Reynolds number. As such the required operating point is achieved by controlling the values of these two non-dimensional quantities by, for example, appropriate choices for the mass flow rate and applied brake torque. However, when the turbine has an atmospheric inlet and uses unconditioned air, variations in ambient pressure, temperature and humidity are introduced. Whilst it is still possible to maintain the required values for the flow coefficient and Reynolds number, the ambient variations affect additional non-dimensional quantities which are related to the blade speed and gas properties. Generally, the values of these additional non-dimensional quantities cannot be controlled and, consequently, they affect the turbine performance. In addition, thermal effects, which are exacerbated by the use of plastic blades, can cause changes in the blade row seal clearance and these also affect the performance. Therefore to obtain measurements with greater accuracy and repeatability, the changes in the uncontrolled non-dimensional quantities must be accounted.

This paper contains four parts. Firstly, it is described how suitable data acquisition parameters can be determined to eliminate short time scale facility unsteadiness within the measurements. Secondly, by the analysis of models, the most appropriate forms for the additional non-dimensional quantities that influence turbine performance are obtained. Since the variations in the uncontrolled non-dimensional quantities affect repeatability the size of the effect on the turbine performance is quantified. Thirdly, a best-fit accounting methodology is described which reduces the effects of the uncontrolled nondimensional quantities on turbine performance provided sufficient directly related measurements are available. Finally, the observations are generalised to high-speed turbomachines.
\end{abstract}




\section{Introduction}

The accounting methodology described in this paper arose out of a systematic investigation into unexplained poor experimental repeatability for the low-speed, two-stage turbine facility. Throughout an experimental programme lasting several weeks, the facility control variables, flow coefficient and Reynolds number, had fractional noise, $\sigma / \mu$, less than $0.01 \%$. However, even after including the effects of humidity within the bellmouth calibration, the measured turbine work coefficient varied by more than $0.5 \%$ whilst a pessimistic error analysis suggested that it ought to be reliable to within $0.1 \%$.

It will be shown that there are five non-dimensional quantities that are relevant in determining turbine performance. The first two are the flow coefficient and Reynolds number and these are controlled at their required values during the experiments. The remaining three non-dimensional quantities are related to the blade speed, gas expansion properties and blade row seal clearances. The values of these are uncontrolled as they are determined by the ambient conditions.

To demonstrate the importance of appropriately accounting for changes in the uncontrolled non-dimensional quantities an illustrative example is presented in Fig. 1. The turbine work coefficient, $\psi$, is shown against one of the uncontrolled quantities, the non-dimensional blade speed, $b$. Two dataset families, representing different turbine geometries, are illustrated by the coloured symbols: black and red. At the design flow coefficient and Reynolds number, six repeat experiments were undertaken for each family (indicated by the hollow symbols). However, the black turbine geometry was tested under ambient conditions which produced lower values of the uncontrolled nondimensional blade speed, $b$. If the uncontrolled variations are ignored, a straight forward average of each family of measurements, $\bar{\psi}$, indicated by the filled square symbol, would suggest that the red geometry is the better of the two. However, because there is a variation in the uncontrolled quantity, $b$, it is necessary to account each dataset family to a common datum, $b_{\text {datum }}$. This can be done by bestfitting each family of data to obtain $\psi_{\text {datum }}$, indicated by the filled circular symbols. By accounting the data to a common datum a more reliable result is obtained: the black geometry is better than the red. 
This illustrative example shows that without accounting for the variations in the uncontrolled non-dimensional quantities experimental results could be misinterpreted. To obtain reliable results it is necessary to know both the sensitivity of the measurements to the uncontrolled quantities and the range over which they vary.

\section{Background}

The flow through low-speed turbines, where the blade Mach number is less than 0.1 , is traditionally considered to be well modelled by assuming the flow to be incompressible (constant density). In such cases the turbine performance is assumed to be just a function of the flow coefficient, which determines the velocity triangles, and the Reynolds number which determines the viscous effects. This is convenient because there are only two variables (mass flow rate and brake torque) which can be adjusted to achieve the required turbine operating point.

However, researchers are aware that there are other non-dimensional quantities that can affect turbine performance. The most common additional quantity, which is introduced in the analysis of high-speed turbomachines, is the non-dimensional blade speed (often just cited as $N / \sqrt{T_{0}}$ ). Similarly, where humidity or different working gases are involved a non-dimensional quantity associated with the gas properties (e.g. adiabatic index $\gamma$ ) must also be included. In cases where thermal expansion, or growth due to centrifugal stress, is significant (e.g. plastic blades) there is a further relevant nondimensional quantity, gap/span. In low-speed turbomachines these additional non-dimensional quantities are generally ignored because they are assumed to have little effect and cannot be directly controlled.

During the experimental programme the low-speed turbine was operated at its design flow coefficient and Reynolds number, however, changes in the ambient conditions caused the following variations. The blade Mach number (typically 0.076 ) varied by $\pm 3 \%$, the relative humidity between $30 \%$ to $90 \%$ and the facility temperature could be more than $10 \mathrm{~K}$ higher in one test compared to another. Using the performance models described later in this paper these, uncontrolled, variations in the ambient conditions produce changes in the turbine work of up to $0.7 \%$ when compared to dry air 
on a standard day, Table 1 . Further, a systematic error of up to $0.45 \%$ would be introduced if the bellmouth calibration did not include the change in the gas constant due to humidity.

The tolerances required for current experiments dictate that the following four steps must be addressed when there are uncontrolled quantities. Firstly, the most appropriate forms for the nondimensional quantities need to be identified. Secondly, a reliable model for the working fluid, in this case humid air, is necessary. Thirdly, the controlled quantities must be at the appropriate operating values. Finally, a reliable methodology is required to account for the uncontrolled quantities not being at the datum values.

Wells and McGrew [1] discussed the effects of different working fluids. Berdanier et al. [2] used a sophisticated model for humid air properties and Cumpsty and Marquis [3] presented a simple model for real gas effects. Rusch and Casey [4] identified the full range of independent variables involved for compressible flow through turbomachines. However, other than Berdanier et al., there has been little published on which of the several forms of the relevant non-dimensional quantities are the most appropriate, nor publications commenting on the sizes of compressibility effects in lowspeed facilities.

\section{Paper outline}

Dimensional analysis will be presented to determine that there are five independent nondimensional quantities relevant to turbine performance. The experimental facility will then be described and the data acquisition techniques justified. A set of baseline performance experiments will be presented to demonstrate that the turbine work coefficient can vary by $0.2 \%$ within a single day even when the flow coefficient and Reynolds number are held fixed. Models for turbine performance and humid air will be presented and examined to identify the appropriate forms for the uncontrolled non-dimensional quantities. These models, along with one for the effects of tip leakage, will be used to show that changes in the turbine work during the baseline experiments correspond to the variation in the uncontrolled quantities.

A methodology, using a best-fit approach, will be described to account for the variations in the uncontrolled non-dimensional quantities provided that a family of directly related data is 
available. The methodology is then extended to performance maps and CFD calculations. Finally, implications for high-speed turbomachines will be discussed.

\section{Dimensional Analysis}

For reliable experiments the number and form of the independent non-dimensional quantities that determine the turbine performance are required. For this analysis the dependent variable considered is the stagnation enthalpy drop across the turbine, $\Delta h_{0}$. The fluid dynamic conditions can be characterised by the stagnation pressure, stagnation temperature and the axial velocity at the reference plane, $P_{0, \text { ref }}, T_{0, \text { ref }}$ and $v_{x, r e f}$, respectively, along with the mid-span blade speed, $U$. The properties of the working gas (including humidity) are characterised by the dynamic viscosity, $\mu$, specific heat capacity at constant pressure, $c_{p}$, and the gas constant, $R$. For geometrical similarity, one length is required and is chosen to be the axial chord of the first stator, $c_{x}$. However, the clearance gaps over the rotor and under the stator vary with temperature so there is another relevant length, gap. Therefore the turbine performance can be expressed as:

$$
\Delta h_{0}=\operatorname{fnc}\left(P_{0, r e f}, T_{0, r e f}, v_{x, r e f}, U, \mu, c_{p}, R, c_{x}, \text { gap }\right)
$$

There are ten variables in total which can be expressed using four base dimensions (mass, length, time and temperature) so from Buckingham's Pi theorem there are expected to be at least six nondimensional quantities. A suitable form for the non-dimensional relationship is:

$$
\frac{\Delta h_{0}}{U^{2}}=f n c(\phi, R e, b, g, c)
$$

The first two non-dimensional quantities are the flow coefficient and the Reynolds number which are defined as:

$$
\phi=\frac{v_{x, \text { ref }}}{U} \quad \text { and } \quad R e=\frac{\rho_{0, r e f}\left(v_{x, r e f} / \cos \alpha_{3}\right) c_{x}}{\mu}
$$

These are the quantities that are traditionally quoted for low-speed experiments. The remaining three non-dimensional quantities have been chosen to have the following forms:

$$
b=\frac{U}{\sqrt{c_{p} T_{0, \text { ref }}}} \quad g=\frac{c_{p}}{R} \quad c=\frac{g a p}{\text { span }}
$$


The appropriate form of the non-dimensional blade speed, $b$, and the gas expansion, $g$, are identified by examining the equations in the compressible polytropic model given in Appendix 1. It is important that the non-dimensional blade speed includes $c_{p}$ rather than $\gamma R$.

For convenience, the representative stator and rotor leakage gaps has been nondimensionalised by the blade span. Usually the non-dimensional clearance, $c$, is taken to be a constant and not explicitly included in the analysis. However, it was observed to be a function of temperature in this facility. Therefore, it is necessary to include the non-dimensional clearance as an independent non-dimensional quantity.

\section{Experimental Facility}

The recently rebuilt Peregrine facility is a two-stage, low-speed turbine which includes representative rotor tip and stator hub leakage paths and cavities, Fig. 2. The blade aerodynamics correspond to current aero-engine technology for low pressure turbines and are summarised in Table 2. Both stator rows are designed to produce similar exit flow angles. However, the first stator has axial inlet flow so it has lower aerodynamic loading. The two rotor rows have identical geometry.

The experimental facility has a volumetric flow rate of approximately $20 \mathrm{~m}^{3} / \mathrm{s}$ so it is generally operated with the external laboratory doors open. Therefore the ambient conditions are uncontrolled as pre-conditioning of the inlet flow is impractical. An inlet bellmouth is used to measure the inlet flow rate and there is a grid at the start of the parallel section to produce a representative level of turbulence intensity of approximately $4 \%$. The turbine shaft is fitted with a torque meter and uses a step-up gearbox to drive an eddy current brake which absorbs the output power. The air flow is drawn through the facility by a variable speed, $315 \mathrm{~kW}$, centrifugal fan.

A close-up meridional view of the working section is shown in Fig. 2b. There are four Kiel probes and a thermocouple at the reference plane $(R e f)$, located approximately half a span upstream of the first stator, which are used to define the reference conditions to non-dimensionalise the measurements. There are seven measurement planes where spanwise and circumferential traverses can be undertaken. The circumferential range is three stator pitches at planes 1 to 6 and five stator pitches at plane 7. The circumferential extent is illustrated in Fig. 2c by the turquoise and blue sectors, 
respectively. There are also eight self-aligning Pitot probes which are distributed across the span and around the circumference at the exit of the turbine (illustrated in green in Fig. 2c).

The current applied to the eddy current brake and the speed of the centrifugal fan are computer controlled to maintain the required flow coefficient (defined at the reference plane) and Reynolds number (defined using the Stator axial chord). To do this, the facility telemetry provides the control system with real-time details of the ambient conditions along with bellmouth pressure drop and shaft speed.

A key feature of the control system is that it contains a simple model for humid air (details in Appendix 2). Once the gas constant for the ambient conditions has been determined, the flow through the turbine is modelled as a perfect gas. Whilst this is not the most sophisticated modelling approach for humid air, it is sufficient because the temperature drop through the turbine is approximately $2 \mathrm{~K}$. It should be noted that the bellmouth calibration uses a time varying value for the gas constant which depends on the ambient conditions.

During the commissioning of the experimental facility both the control system and facility hardware were extensively refined to minimise the variation of the flow coefficient and Reynolds number during operation. For example, by undertaking a time-accurate simulation of both the aerodynamics of the facility and the response of the control system, using the Peregrine Unsteady Aerodynamic Model (PUAM) [5], a fluid dynamic coupling between the exit swirl from the turbine affecting the performance of the downstream centrifugal fan was identified. The fluid dynamic coupling was eliminated by installing a honeycomb upstream of the centrifugal fan which both improved the steadiness of the operating point (fractional noise reduced by $60 \%$ ) and increased the maximum Reynolds number that could be achieved by $8 \%$ (eliminated bulk co-swirl entering the fan).

During the experiments, data is acquired from the facility control computer, for the torque, speed, mass flow rate etc., and from the pressure transducers over a one second interval. This is referred to as a one-second sample. The experimentally determined fractional noise (expressed as $\sigma / \mu)$ for a one-second sample are listed in Table 3.

\section{Selection of the number of samples, $N$}


The majority of measurements would be expected to lie between $\pm 3 \sigma$ so to achieve repeatability to within $0.1 \%$ the fractional noise $(\sigma / \mu)$ must be of the order $0.01 \%$.

For the controlled quantities, flow coefficient and Reynolds number, the factional noise in a one-second sample, although repeatable, is too large, see Table 3. Provided that the noise is statistically independent, the fractional noise can be reduced by taking multiple one-second samples (averaging over a longer time). The number of samples, $N$, required can be estimated using:

$$
\left(\frac{\sigma}{\mu}\right)_{N \text { samples }}=\frac{1}{\sqrt{N}}\left(\frac{\sigma}{\mu}\right)_{1 \mathrm{sec}}
$$

This has been experimentally confirmed by examining the average value of the controlled independent quantities for repeated experiments with different numbers of one-second samples, see Fig. 3. If $N \geq 100$ the fractional noise should be less than $0.01 \%$ in the controlled quantities. The noise bandwidth, determined by an autocorrelation, for the flow coefficient and Reynolds number is about five seconds.

For dependent quantities such as the work coefficient and efficiency the fractional noise is also too large and is not experimentally repeatable, see Table 3 . This is because variations in the uncontrolled quantities, $b, c$ and $g$, introduce effects which are not statistically independent. For example, with reference to Fig. 1, taking more measurements for the black geometry may reduce the fractional noise but will not necessarily improve the comparison with the red geometry as the change in the uncontrolled quantity, $b$, behaves like a "bias".

If there were no uncontrolled independent quantities then it may be possible to use a sensitivity analysis to estimate the fractional noise in the dependent quantity from the independent quantity. For example, for incompressible flow, the stage loading can be expressed as:

$$
\psi_{s t g}=\phi\left(\tan \alpha_{3}-\tan \alpha_{4}^{\text {rel }}\right)-1
$$

Evaluating the above, using data from Table 2, gives:

$$
\frac{\delta \psi}{\psi}=1.50 \frac{\delta \phi}{\phi} \quad \text { so } \quad\left(\frac{\sigma}{\mu}\right)_{\psi}=1.50\left(\frac{\sigma}{\mu}\right)_{\phi}
$$


The above would suggest that if the fractional noise in the flow coefficient were $0.01 \%$, then the flow coefficient should be repeatable to $0.06 \%$ (assuming $\pm 3 \sigma$ ) and therefore the work coefficient ought to be repeatable to within $0.09 \%$.

\section{Baseline Performance Experiments}

To investigate the apparent lack of repeatability of the measurements, a set of twenty-seven consecutive baseline performance experiments were undertaken. The baseline configuration is defined as the controlled quantities at the design operating values and the same nominal geometry. The facility had been operating for over an hour before the first baseline performance experiment was undertaken. In an attempt to minimise the variation in the measured quantities, each individual baseline performance experiment involved averaging 600 one-second samples and so took ten minutes.

The fractional variation in the flow coefficient and Reynolds number for the twenty-seven baseline experiments are shown in Fig. 4. The observed fractional noise in the controlled quantities is less than $0.0014 \%$ (see Table 4). This agrees well with the values estimated using Eqn. (5) with $N=600$ (also shown Table 4). From Eqn. (7), the fractional noise in the work coefficient ought to be approximately $0.002 \%$. This suggests that the turbine operating point ought to be repeatable for the baseline performance experiments.

The turbine work coefficient measured during the baseline performance experiments are shown in Fig. 5. There is a gradual decrease during the latter part of the day and an overall peak to peak variation of $0.2 \%$. The accuracy of the facility instrumentation cannot explain the observed $0.2 \%$ variation. Therefore, there must be another cause for the lack of experimental repeatability.

\section{Cause of Lack of Repeatability}

The turbine control software examines the ambient conditions in real-time and controls the flow coefficient and Reynolds number at the required values, see Fig. 4. The three remaining independent non-dimensional quantities $(b, g$ and $c)$ are uncontrolled and their values depend on the ambient conditions. The duration of each baseline performance experiment is ten minutes so, provided that the ambient conditions do not vary dramatically, it is appropriate to examine just the average 
value of the three uncontrolled non-dimensional quantities in each experiment. These are shown in Fig. 6. Clearly the values vary during the baseline performance experiments.

To show that the observed variations in the uncontrolled quantities are large enough to cause the lack of repeatability in the turbine work coefficient, shown in Fig. 5, the sensitivities of the turbine work coefficient to each of the uncontrolled quantities are required. These sensitivities will be obtained by applying models for the effects of non-dimensional blade speed, gas properties and nondimensional clearance on the turbine work. The advantage of examining the turbine work is that it is primarily an inviscid process so it can be modelled without having to introduce empirical viscous correlations.

\section{Compressible Polytropic Turbine Model}

The work extraction for a single stage turbine with flow at a constant radius, is derived in Appendix 1, see Fig. 2b for locations. The stage 1 loading is given by Eqn. (A1.1):

$$
\psi_{s t g}=\frac{\Delta h_{0}}{U^{2}}=\left(\frac{v_{x 3}}{U} \tan \alpha_{3}-\frac{v_{x 4}}{U} \tan \alpha_{4}^{\text {rel }}\right)-1
$$

The above equation shows that the stage loading is primarily a function of the non-dimensional axial velocity at stator and rotor exit. By continuity, the axial velocity is only affected by the density ratio which is closely related to the stagnation temperature ratio which is given by Eqn. (A1.6):

$$
\frac{T_{04}}{T_{0, r e f}}=1-\psi_{s t g} \frac{U^{2}}{c_{p} T_{0, r e f}}=1-\psi_{s t g} b^{2}
$$

The above equation, and all the other equations related to the temperature ratios, involve the nondimensional blade speed, $b$, defined by Eqn. (4). Therefore this is the appropriate non-dimensional quantity directly related to energy transfer.

Traditionally, the performance of low-speed turbines is assumed to be essentially independent of the non-dimensional blade speed, $b$. This assumption can be examined by solving the equations in Appendix 1 for the two-stage turbine using Turbine Performance (TPER) [6]. The variation of the turbine work coefficient and the non-dimensional axial velocities through the blades rows are shown in Fig. 7 for a range of non-dimensional blade speeds. The incompressible assumption corresponds to zero non-dimensional blade speed. The nominal non-dimensional blade speed $\left(b_{\text {expt }}=0.0485\right)$ is shown 
on the figures and even though this corresponds to a blade Mach number of less than 0.1 there are clear signs of the effects of compressibility.

\section{Sensitivity to non-dimensional blade speed, $b$}

For the range of non-dimensional blades speeds encountered during the experimental programme, the fractional variation in the turbine work coefficient is shown in Fig. 8. One curve corresponds to an isentropic turbine and the other curve to a turbine with an efficiency of $90 \%$. The effect of varying the non-dimensional blade speed is more significant at lower turbine efficiencies because the density drop through the turbine is larger. The calculations assumed dry air, fixed inlet stagnation temperature, no change in leakage gaps and both the flow coefficient and Reynolds number were at the design values (only the inlet stagnation pressure was varied).

From Fig. 8 it is clear that the variation is primarily linear. The sensitivity of the turbine work coefficient to the variation in the non-dimensional blade speed are 4.04 and 4.46 (corresponding to the isentropic and $90 \%$ efficient turbine).

\section{Model for Humid Air}

A simple way to model humid air (mixture of water vapour and air) is the semi-perfect gas approach, $c_{p}(T)$. Whilst this has limitations, it is sufficiently general to demonstrate the effects of humidity without the need for extensive databases of real gas properties. The values and correlations used are listed in Appendix 2.

For a non-reacting mixture at low pressure, Dalton's Law for partial pressures states:

$$
P_{p, v a p} \dot{V}=\dot{m}_{\text {vap }} R_{\text {vap }} T \quad \text { and } \quad P_{p, a i r} \dot{V}=\dot{m}_{\text {air }} R_{\text {air }} T
$$

where the subscripts vap and air refer to the water vapour and air respectively. The pressure of the mixture is given by:

$$
P=P_{p, v a p}+P_{p, a i r}
$$

Combining Eqns (10) and (11) yields the appropriate gas constant for humid air:

$$
R_{\text {hmd }}=\frac{\dot{m}_{v a p} R_{\text {vap }}+\dot{m}_{\text {air }} R_{a i r}}{\dot{m}_{\text {vap }}+\dot{m}_{\text {air }}}
$$

The corresponding value for the specific heat capacity at constant pressure for humid air is given by: 


$$
c_{p, \text { hmd }}=\frac{\dot{m}_{v a p} c_{p, v a p}+\dot{m}_{a i r} c_{p, a i r}}{\dot{m}_{v a p}+\dot{m}_{\text {air }}}
$$

A convenient way to quantify the partial pressure of the water vapour is by the definition of the relative humidity:

$$
R H=P_{p, v a p} / P_{\text {sat }}(T)
$$

where $P_{s a t}(T)$ is the saturated vapour pressure corresponding to the temperature of the humid air. The above equations can be rearranged to obtain:

$$
\frac{\dot{m}_{\text {vap }}}{\dot{m}_{\text {air }}}=\frac{P_{p, v a p}}{P-P_{p, v a p}} \frac{R_{\text {air }}}{R_{\text {vap }}}
$$

Equations (12) and (13) show that it is the ratio $\dot{m}_{\text {vap }} / \dot{m}_{\text {air }}$ (the absolute humidity) which determines the change in $R_{h m d}$ and $c_{p, h m d}$ which are the gas properties relevant to turbomachinery. Although the saturation vapour pressure is typically less than $3 \%$ of an atmosphere, it is a strong function of temperature, Eqn. (A2.3). Hence $\dot{m}_{v a p} / \dot{m}_{\text {air }}$ depends strongly on the relative humidity and the ambient temperature. On most operating days there is less than $1 \%$ of water vapour in the humid air but, on hot humid days, it could be up to $2 \%$.

As observed by Berdanier et al. [2], because the fractional change in ambient pressure is quite small (typically $\pm 2 \%$ ), there is only a slight variation in the absolute humidity with ambient pressure (fixed temperature and relative humidity).

Because the temperature drop through the turbine is about $2 \mathrm{~K}$, the air and water vapour properties within the working section are assumed to be the same as the ambient. Equations (12) and (13) show that, provided condensation does not occur, the properties, $R_{h m d}$ and $c_{p, h m d}$, do not change through the turbine and so the flow can be modelled as a perfect gas.

\section{Effects Which Must Be Included}

Humid air has a lower density than air. This is because the gas constant for water vapour is approximately $60 \%$ larger than that for air (Table 5) so Eqn. (12) shows that $R_{h m d}$ increases with humidity. Therefore, at fixed temperature and pressure, the density of humid air changes by about $-0.6 \%$ at $90 \%$ relative humidity compared to dry air. If this decrease in ambient density were 
not accounted for in the bellmouth calibration the volumetric flow would be approximately $0.3 \%$ high. Using Eqns (6) and (7) the corresponding fractional increase in turbine stage loading would be $0.45 \%$.

\section{Sensitivity to non-dimensional gas expansion, $g$}

The sensitivity of the turbine work to the non-dimensional gas expansion, $\mathrm{g}$, can be assessed using the compressible polytropic model. Note that the flow coefficient, Reynolds number, and the non-dimensional blade speed must be held fixed. The effects of $g=c_{p} / R$ on the turbine work coefficient for the isentropic and $90 \%$ efficient turbine assumptions are shown in Fig. 9 and the sensitivity is 0.042 .

\section{Model for tip-leakage}

Extending the tip-leakage model of Yoon et al. [7] to include both shrouded stator-hub and rotor-tip leakage flows on the output power of a turbine stage, Appendix 3, yields the following relationship:

$$
\left.\frac{\delta \psi}{\psi}\right|_{\text {leak }}=-\frac{\delta \dot{m}_{\text {leak }}}{\dot{m}} \frac{\phi\left(3 \tan \alpha_{2}-2 \tan \alpha_{3}^{\text {rel }}\right)-1}{\phi\left(\tan \alpha_{2}-\tan \alpha_{3}^{\text {rel }}\right)-1}
$$

where $\delta \dot{m}_{\text {leak }}$ is the representative variation in the leakage flow due the changes in the seal gaps as a consequence of thermal effects. For the turbine at design, the above becomes:

$$
\left.\frac{\delta \psi}{\psi}\right|_{\text {leak }}=-3.23 \frac{\delta \dot{m}_{\text {leak }}}{\dot{m}}
$$

For a 50\% reaction single-stage turbine with just rotor-tip leakage Yoon et al. estimated the constant of proportionality to be -1.84 and they measured a value of -1.95 . Thus the larger value, -3.23 , for the Peregrine turbine (52\% reaction) which has both stator-hub and rotor-tip leakage is reasonable.

In the experimental facility the casings rings are steel, the rotor disc assembly is aluminium and the blades are a polyurethane plastic. The combination of plastic blades and a 0.7 hub-to-tip ratio introduces an increased sensitivity of the size of the stator-hub and rotor-tip leakage gaps to the operating temperature. The resultant variation in the non-dimensional clearance, c=gap/span, is shown in Fig. 10. 
Determining the relationship between the physical size of the leakage gap and the actual leakage mass flow rate is not straightforward. Here it will be estimated using Denton's [8] simple model for leakage over or under a shrouded blade:

$$
\frac{\delta \dot{m}_{\text {leak }}}{\dot{m}} \approx \delta\left(\frac{g a p}{\text { span }}\right) \frac{1}{\sqrt{N_{\text {seal }}}} \frac{1}{\cos \alpha_{\text {exit }}}
$$

where $N_{\text {seal }}$ is the number of knife-edged seals and $\alpha_{\text {exit }}$ is the exit flow angle measured in the blade frame.

\section{Sensitivity to non-dimensional clearance, $c$}

By combining Eqns (17) and (18), the sensitivity of the turbine work to changes in nondimensional clearance is -9.64 .

\section{Effect of the Uncontrolled Quantities}

In the previous sections, models have been used to estimate the sensitivity of the turbine work coefficient to changes in the non-dimensional blade speed, gas expansion and gap/span. These sensitivities are summarised in Table 6. However, to determine the size of the effect on the turbine work the sensitivity must be combined with the range over which the quantity varies. Therefore, the range of the uncontrolled non-dimensional quantities measured during the baseline performance experiments and the estimated effect on the turbine work coefficient are also listed in Table 6.

The non-dimensional gas expansion is estimated to produce only a $0.001 \%$ change in turbine work. This is very small suggesting that the effects of humidity only need to be incorporated in to the bellmouth calibration. Both the non-dimensional blade speed and non-dimensional clearance are estimated to each produce at least a $0.1 \%$ variation in the turbine work. Therefore, if the effects combine they would match the observed variation of $0.2 \%$.

\section{Accounting to a Common Datum}

In the previous section, it has been shown that the variation in the turbine work using sensitivities estimated from the models are comparable to those observed during the baseline performance experiments. Further, the analysis has also demonstrated that for small variations in the uncontrolled non-dimensional quantities a linearised analysis is possible, thus: 


$$
\begin{gathered}
\psi\left(b_{i}, g_{i}, c_{i}\right)=\psi_{d t m}+\frac{\partial \psi}{\partial b} \Delta b_{i}+\frac{\partial \psi}{\partial g} \Delta g_{i}+\frac{\partial \psi}{\partial c} \Delta c_{i} \\
\Delta b_{i}=b_{i}-b_{d t m} \quad \text { etc. }
\end{gathered}
$$

where $\left(b_{d t m}, g_{d t m}, c_{d t m}\right)$ are conveniently chosen datum values for the uncontrolled quantities, $(\partial \psi / \partial b, \partial \psi / \partial g, \partial \psi / \partial c)$ are the sensitivities and $\psi_{d t m}$ is the corresponding (unknown) value of the turbine work coefficient. Therefore each of the baseline performance measurements can be expressed as:

$$
\psi_{i}=\psi\left(b_{i}, g_{i}, c_{i}\right)+\varepsilon_{i}
$$

where $\psi_{i}$ is the measured performance, $\psi\left(b_{i}, g_{i}, c_{i}\right)$ is the idealised value associated with the given uncontrolled non-dimensional quantities and $\varepsilon_{i}$ is the (assumed random) experimental noise. If the sensitivities are known then it is possible to take the measured performance $\psi_{i}$ and account for the difference between the actual and datum values of the uncontrolled quantities. Thus:

$$
\psi_{i, \text { accounted }}=\psi_{i}-\frac{\partial \psi}{\partial b} \Delta b_{i}-\frac{\partial \psi}{\partial g} \Delta g_{i}-\frac{\partial \psi}{\partial c} \Delta c_{i}
$$

where $\psi_{i, \text { accounted }}$ is the accounted value that would be expected if the all the uncontrolled nondimensional quantities had the required datum values and the measurement contained just the (random) experimental noise $\varepsilon_{i}$.

\section{Model sensitivities applied to the baseline data}

Using the estimated sensitivities obtained from the models (Table 6), the accounted values for each of the baseline performance experiments are shown in Fig. 11 (green). The measured, unaccounted, values are shown for comparison (reproduced from Fig. 4). Clearly, accounting the baseline performance experiments using the model sensitivities has improved the consistency of the turbine work. The peak-to-peak variation and fractional noise are summarised in Table 7.

\section{Best-fit sensitivities applied to the baseline data}

An alternative way to estimate the sensitivities is to use a best-fit approach. This is done by combining Eqns (19) and (21) to produce an expression for the (random) experimental noise $\varepsilon_{i}$ in terms of the unknown sensitivities: 


$$
\varepsilon_{i}=\psi_{i}-\left(\psi_{d t m}+\frac{\partial \psi}{\partial b} \Delta b_{i}+\frac{\partial \psi}{\partial g} \Delta g_{i}+\frac{\partial \psi}{\partial c} \Delta c_{i}\right)
$$

Because the baseline performance experiments are expected to be equivalent (same notional geometry and operating point) they can be thought of as a directly related family of data. By solving the best-fit problem to minimise the total error:

$$
(\text { Total Error })^{2}=\sum_{\text {family }} \varepsilon_{i}^{2}
$$

it is possible, provided the family has more than four data points, to determine best-fit values for the unknowns: $\psi_{d t m}$ and the three sensitivities $(\partial \psi / \partial b, \partial \psi / \partial g, \partial \psi / \partial c)$. These best-fit sensitivities are listed in Table 6 and the best-fit accounted values for the turbine work coefficient are plotted in Fig. 11 (red). The best-fit sensitivities produce slightly more consistent data than the model sensitivities (see discussion).

A more significant advantage to using the best-fit sensitivities, rather than those obtained from a model, is that any quantity can be accounted (whether or not a model is available) provided that there are sufficient directly related measurements to allow the best-fit technique. Thus best-fit accounting is a post-experiment technique.

\section{Accounting Turbine Performance Maps}

Accounting a single family of directly-related, repeated experiments involves only one datum for each of the uncontrolled non-dimensional quantities. However, when the performance map of the turbine is considered, i.e. for a range of flow coefficients and Reynolds numbers, there is a different nondimensional blade speed at each operating point. In such circumstances, for each Reynolds number, it is necessary to select a consistent datum for the uncontrolled non-dimensional quantities and use that datum to account the data accordingly. This is achieved by noting that the product of the flow coefficient and the non-dimensional blade speed is:

$$
b \phi=\frac{V_{x}}{\sqrt{c_{p} T_{0, r e f}}}
$$


which would be expected to be constant at each Reynolds number (and to be, obviously, related between the different Reynolds numbers). The appropriate datum at each individual flow coefficient is therefore defined as:

$$
b_{d t m}=\frac{(b \phi)_{d t m}}{\phi}
$$

By using the above approach it is possible to best-fit account the efficiency curves which are shown in Fig. 12 for three Reynolds numbers over a range of flow coefficients. The fractional noise in the unaccounted and accounted data is shown by the red and yellow bands, respectively. Similar to previous demonstrations, the accounting approach produces a much more consistent performance map. The noise in the measurements is reduced by $60 \%, 50 \%$ and $40 \%$ for the $100 \%, 85 \%$ and $70 \%$ Reynolds number cases respectively.

\section{Accounting CFD Calculations}

CFD calculations were undertaken to investigate the aerodynamics of the flow through the two-stage turbine including fully meshed stator-hub and rotor-tip cavities. Both steady and unsteady calculations were undertaken using Turbostream [9] with the Spalart-Allmaras turbulence model. For the time-accurate calculations, a total of fourteen blade passages, three stator and four rotor rows in each stage, were included. The computational domain contained approximately $80 \times 10^{6}$ cells and the calculations were undertaken on the Wilkes GPU cluster at the High Performance Computing Service at Cambridge University.

The version of Turbostream used does not include a low-Mach number pre-conditioner so the time accurate calculations were run at double the non-dimensional blade speed of the experiments. The viscosity was adjusted to obtain the Reynolds number at the design flow coefficient.

Comparisons between the experimental data and the steady and unsteady calculations at measurement plane 6 (Fig. 2b) are shown in Fig. 13. Clearly, both the steady and unsteady calculations are only in qualitative agreement with the measurements. This is due to the difference in the non-dimensional blade speed of the experiment compared to the computations. Figure $7 \mathrm{~b}$ shows the axial velocities at each measurement plane for a range of non-dimensional blade speed using the compressible polytropic model (TPER [6]) and demonstrates the size of the discrepancy. It is possible 
to apply an accounting methodology using information at the two values of the non-dimensional blade speed $\left(b_{\text {expt }}\right.$ and $b_{c f d}=2 \times b_{\text {expt }}$ ). By using the ratio of the two values a scale factor can be determined and applied to the CFD axial velocity profiles. Similar scale factors are determined for the tangential velocity and the stagnation pressures. Consequently, the accounted CFD profiles are in much better agreement with the measurements.

Considering the profiles in Fig. 13, it is clear that the accounted non-dimensional axial velocity matches very well with the measurements as the scale factor is primarily determined by continuity. It is clear that the unsteady calculation is better at capturing the endwall secondary flow features than the steady mixing plane approach. The accounted non-dimensional tangential velocity also matches quite well but, because it involves an assumption of fixed blade-frame relative flow angle it is not as good as the axial velocity. The accounted stagnation pressure profiles do not match exactly because the CFD calculation assumed a fully turbulent boundary layer which produced larger wakes than those measured.

\section{Generalisation to High-Speed Machines}

Although the experiments discussed within this paper have been undertaken on a low-speed facility, the requirement to account the data families stems from the changes in the ambient conditions affecting the uncontrolled non-dimensional quantities. Many high-speed turbine test facilities have an atmospheric inlet and pre-compress and post-compress the flow through the turbine test section. Consequently, such tests are also liable to be affected by changes in ambient conditions, especially the humidity. Extending the work discussed here indicates that some aspects of humidity need to be assessed in setting the turbine operating point whilst others, such as the change in the nondimensional gas expansion can only be addressed by post-test accounting a family data. Further, the form of the non-dimensional blade speed, $b$, given in Eqn. (4) appropriately includes the dependency on the real gas properties to correctly scale the work transfer.

\section{Discussion}

The first part of this paper has shown how variations in ambient conditions can affect lowspeed turbine performance through uncontrolled changes in three non-dimensional quantities. These 
changes can be significant compared to the desired experimental accuracy and may previously have been attributed to a lack of repeatability. Further, it is apparent that the experimental facility never settles to a fixed operating point.

The relationships between changes in the ambient conditions and the uncontrolled nondimensional quantities are summarised in Fig. 14. Also shown on the same figure is the expected variation in the turbine work coefficient associated with the range of ambient variations encountered during the experimental programme. The sizes are significant given the performance levels of current turbomachinery design.

The best-fit accounting methodology developed within this paper permits the effects of the uncontrolled non-dimensional quantities to be eliminated from an experimental investigation provided that a family of directly related experiments can be undertaken. The best-fit approach is better than the one based on model sensitivities because reliable models may not be available (e.g. viscous dominated quantities).

Comparing the values listed in Table 6 shows that the model and best-fit sensitivities agree well for the non-dimensional blade speed which is essentially an inviscid effect. The two sensitivities for the non-dimensional clearance are only roughly similar probably because viscous effects are important in determining the exact leakage through a seal. A further consideration is that the actual clearance gap had to be estimated by tracking the temperatures of the casings, blades and rotor assembly during the experiments. Each component has its own thermal time constant so, in the absence of direct gap measurements, it was necessary to undertake a time dependent thermal analysis (full details in Evans [10]).

Although the sensitivities due to changes in the gas properties are very different, the actual effects on the turbine work are small. However, the way in which the gas properties are modelled within the control code does not include the variation of the dynamic viscosity with humidity, only the variation with temperature is included. Sengers and Kamgar-Parsi [11] give the dilute gas limit for dynamic viscosity of water vapour and when combined with a transport model for the viscosity of humid air, Mason and Saxena [12], there is a slight dependence on the absolute humidity at higher 
temperatures. The major effect is still the dependency on temperature. However, further work is required.

The robustness of the best-fit accounting technique depends on both the number of measurements within the directly related family and the relative position of the datum values compared to the experimental average. Ideally, the datum values should be within the experimental range. Therefore when planning an experimental investigation where there are uncontrolled quantities careful attention must be given to the required number of accounting parameters.

\section{Conclusions}

It is well established that the performance of low-speed turbines depends on the flow coefficient and Reynolds number. Usually these two non-dimensional quantities are controlled. This work has shown the following:

- There are three additional non-dimensional quantities that can affect the performance of lowspeed turbines: the non-dimensional blade speed $(b)$, gas expansion $(g)$ and blade row seal clearance $(c)$.

- By examining the work transfer within a turbomachine, the appropriate form for the nondimensional blade speed is $b=U / \sqrt{c_{p} T_{0, r e f}}$. This form includes $c_{p}$ so any changes in the gas properties is correctly included within the work transfer (whereas the blade Mach number does not).

- For an isentropic process of a perfect gas the appropriate form for the non-dimensional gas expansion, or compression, is $g=c_{p} / R$. The turbine model used in this paper assumed a polytropic process for irreversibility and consequently the above form is still appropriate.

- For turbine facilities where the working fluid depends upon ambient conditions some or all of three additional non-dimensional quantities have values which are uncontrolled. Pre-heating, precompression can provide control over some of the additional quantities.

- For the low-speed experimental facility variations in ambient conditions affect the values of the three uncontrolled non-dimensional quantities. The variations in the uncontrolled non- 
dimensional quantities are sufficiently large to generate changes in the turbine performance which appear as lack of repeatability.

- A post-experiment best-fit accounting methodology has been developed that can reduce the effect of the uncontrolled non-dimensional quantities on any turbine performance parameter provided a sufficient number of directly related repeat measurements are available.

- The best-fit accounting methodology has been demonstrated and applied to baseline performance experiments, turbine performance maps.

- It is also possible to use an accounting methodology on CFD calculations which have been undertaken at different non-dimensional blade speeds provided that a reliable turbine performance model is available.

\section{Acknowledgments}

The authors are grateful to Rolls-Royce plc who supported this work through SAMULET Project 1, in collaboration with the TSB (Ref.: AB265C) and the EPSRC (Ref.: EP/H001395/1), and for their permission to publish. The authors also gratefully thank Mr. D. Basham for his skill and care in rebuilding the experimental facility, and to Mr. N. Houghton and Mr. A. Ross for their roles in the mechanical design and manufacture of the components. The authors are also grateful to Prof. $\mathrm{H}$. Hodson for initiating the re-build and for many valuable conversations with Dr. J. Adamczyk and Dr.

T. Hynes.

\section{Nomenclature}

$$
\begin{aligned}
A & =\text { annulus cross-sectional area } \\
b & =\text { non-dimensional blade speed, } U / \sqrt{c_{p} T_{0, r e f}} \\
c & =\text { non-dimensional clearance, gap } / \text { span } \\
c_{x} & =\text { axial chord (first stator) } \\
c_{p} & =\text { specific heat capacity at constant pressure } \\
f_{s}, f_{r} & =\text { stator-hub, rotor-tip leakage fraction } \\
g & =\text { non-dimensional gas expansion, } c_{p} / R
\end{aligned}
$$


gap $=$ rotor tip and stator hub leakage gap

$\Delta h_{0}=$ stagnation enthalpy drop

$\dot{m}=$ mass flow rate

$\dot{m}_{\text {vap }} / \dot{m}_{\text {air }}=$ absolute humidity

$M=$ molar mass

$N=$ number of knife-edge seals

$P, P_{0}=$ static, stagnation pressure

$P_{p}=$ partial pressure

$(q / \bar{q})-1=$ fractional variation $(\bar{q}=$ mean $)$

$R=$ gas constant, $\Re / M$

$\operatorname{Re}=$ Reynolds number, $\rho_{0, r e f}\left(v_{x, \text { ref }} / \cos \alpha_{3}\right) c_{x} / \mu$

$R H=$ relative humidity

$\Re=$ gas constant $\left(8.3144621 \mathrm{~kJ} \mathrm{kmol}^{-1} \mathrm{~K}^{-1}\right)$

$T, T_{0}=$ static, stagnation temperature

$U$ = blade speed at mid-span

$v_{x}, v_{\theta}=$ axial, tangential velocity

$\dot{V}=$ volumetric flow rate

$\gamma=$ adiabatic index

$\eta_{p}=$ polytropic efficiency (static conditions)

$\eta_{t t}=$ total-to-total efficiency

$\mu=$ dynamic viscosity

$\rho=$ density

$(\sigma / \mu)=$ fractional noise (standard deviation/mean)

$\phi=$ flow coefficient, $v_{x} / U$

$\psi=$ stage loading coefficient, $\Delta h_{0} / U^{2}$ 


\section{Subscripts}

$$
\begin{aligned}
\text { air } & =\text { air (dry) } \\
h m d & =\text { humid mixture } \\
r e f & =\text { reference location (upstream of first stator) } \\
\text { vap } & =\text { water vapour }
\end{aligned}
$$$$
\text { 1-7 = measurement plane (Fig. 2b) }
$$ 


\section{References}

[1] Well, R. J., and McGrew, J. M., 1967, "The Use of Gases Other Than Air in the Acoustical Testing of Model Compressors", Proc. ASME 1967 Gas Turbine Conference and Products Show Houston, Texas, March 5-9 1967, Paper No. 67-GT-27.

[2] Berdanier, R. A., Smith, N. R., Fabian, J. C., and Key, N. L., 2015, "Humidity Effects on Experimental Compressor Performance-Corrected Conditions for Real Gases", J. Turbomach., 137(3), p.031011.

[3] Cumpsty, N. A., and Marquis, A. J., 2014, "An Approximate Method to Obtain Thermodynamic Gas Properties for Use in Gas Turbines", Proc. ASME Turbo Expo 2014, Düsseldorf, Germany, June 16-20 2014, Paper No. GT2014-26205.

[4] Rusch, D., and Casey, M., 2013, “The Design Space Boundaries for High Flow Capacity Centrifugal Compressors", ASME J. Turbomach., 135(3), p.031035.

[5] Longley, J. P., 2014, "Peregrine Unsteady Aerodynamic Model (PUAM)", Computer Code, Cambridge.

[6] Longley, J. P., 2015, “Turbine Performance (TPER)”, Computer Code, Cambridge.

[7] Yoon, S., Curtis, E. M., Denton, J. D., and Longley, J. P., 2014, "The Effect of Clearance on Shrouded and Unshrouded Turbines at Two Levels of Reaction", ASME J. Turbomach., 136(2), p.021013.

[8] Denton, J. D., 1993, “The 1993 IGTI Scholar Lecture: Loss Mechanisms in Turbomachines”, ASME J. Turbomach., 115(4), pp. 621-656.

[9] Brandvik, T., and Pullan, G., 2011, "An Accelerated 3D Navier-Stokes Solver for Flows in Turbomachines", ASME J. Turbomach., 133(2), p.021025.

[10] Evans, K. R., 2015, "Clocking in Multi-Stage Axial Turbines", Ph.D. Thesis, Cambridge University, Cambridge.

[11] Sengers, J. V., and Kamgar-Parsi, B., 1984, "Representative Equations for the Viscosity of Water Substance”, J. Phys. Chem. Ref. Data, 13(1), pp. 185-205. 
[12] Mason, E. A., and Saxena, S. C., 1958, "Approximate Formula for the Thermal Conductivity of Gas Mixtures”, Phys. Fluids, 1(5), pp. 361-369.

[13] Chase, M. W., Jr., Davies, C. A., Downey, J. R., Jr., Frurip, D. J., McDonald, R. A., and Syverud, A. N., 1985, "JANAF Thermochemical Tables Third Edition", J. Phys. Chem. Ref. Data, 14(1).

[14] Buck, A. L., 1981, "New Equations for Computing Vapour Pressure and Enhancement Factor", J. Appl. Meteorol., 20(12), pp. 1527-1532. 


\section{Appendix 1: Compressible Turbine Model}

Using the numbering of the measuring planes shown in Fig. $2 b$ an analytic model for the turbine stage loading will be described which includes the effects of compressibility and the necessary perfect gas properties. The equations will then be examined to determine the appropriate choice for the two non-dimensional quantities which characterise the blade speed and gas expansion respectively.

The stage 1 loading can be written as:

$$
\psi_{s t g}=\frac{\Delta h_{0}}{U^{2}}=\left(\frac{v_{x 3}}{U} \tan \alpha_{3}-\frac{v_{x 4}}{U} \tan \alpha_{4}^{\text {rel }}\right)-1
$$

Applying continuity between the reference location and each measurement plane yields:

$$
\frac{v_{x 3}}{U}=\frac{v_{x, r e f}}{U} \frac{A_{r e f}}{A_{3}} \frac{\rho_{r e f}}{\rho_{3}}=\phi \frac{A_{r e f}}{A_{3}} \frac{\rho_{r e f}}{\rho_{3}} \quad \text { etc. }
$$

The density ratio at each measurement plane is affected by the efficiency of the turbomachine. The static-to-static polytropic efficiency, $\eta_{p}$, is a convenient way of including this effect:

$$
\frac{\rho_{\text {ref }}}{\rho_{3}}=\left(\frac{T_{r e f} / T_{0, r e f}}{T_{3} / T_{0, r e f}}\right)^{\frac{\gamma}{(\gamma-1) \eta_{p}}-1} \text { etc. }
$$

All the temperature ratios can be expressed as follows:

$$
\begin{gathered}
\frac{T_{r e f}}{T_{0, r e f}}=1-\frac{1}{2}\left(\frac{v_{x, r e f}}{U}\right)^{2} \frac{U^{2}}{c_{p} T_{0, r e f}}=1-\frac{1}{2} \phi^{2} \frac{U^{2}}{c_{p} T_{0, r e f}} \\
\frac{T_{3}}{T_{0, r e f}}=1-\frac{1}{2}\left(\frac{v_{x 3}}{U}\right)^{2} \frac{1}{\cos ^{2} \alpha_{3}} \frac{U^{2}}{c_{p} T_{0, r e f}}
\end{gathered}
$$

The work extraction across the rotor yields:

$$
\frac{T_{04}}{T_{0, r e f}}=1-\psi_{s t g} \frac{U^{2}}{c_{p} T_{0, r e f}}
$$

so:

$$
\frac{T_{4}}{T_{0, r e f}}=1-\left(\psi_{s t g}+\frac{1}{2}\left(\frac{v_{x 4}}{U}\right)^{2} \frac{1}{\cos ^{2} \alpha_{4}^{r e l}}+\frac{v_{x 4}}{U} \tan \alpha_{4}^{\text {rel }}+\frac{1}{2}\right) \frac{U^{2}}{c_{p} T_{0, r e f}}
$$


Equations (A1.1) to (A1.7) determine the turbine operating point (assuming that the efficiency, areas and flow angles are known). In these equations the blade speed and gas properties occur in the following two non-dimensional quantities:

$$
\frac{U}{\sqrt{c_{p} T_{0, r e f}}}=b \quad \text { and } \quad \frac{\gamma}{\gamma-1}=\frac{c_{p}}{R}=g
$$

The non-dimensional blade speed, $b$, occurs in all the energy Eqns (A1.4) to (A1.7) and the nondimensional gas expansion, $g$, appears in the isentropic and polytropic equations, (A1.3).

\section{Appendix 2: Humid Air}

The expressions used to determine the properties of humid air when modelled as a perfect gas are listed in Table 5. Air and water vapour are modelled as a semi-perfect gas with the following specific heat capacity at constant pressure:

$$
\begin{aligned}
& C_{p, \text { air }}=1004.27+0.0423(T-288.15) \mathrm{J} \mathrm{kg}^{-1} \mathrm{~K}^{-1} \\
& C_{p, \text { vapour }}=1862.21+0.210(T-288.15) \mathrm{J} \mathrm{kg}^{-1} \mathrm{~K}^{-1}
\end{aligned}
$$

where $T$ is in Kelvin and the data have been derived by curve-fitting data from [13].

From Buck [14], a correlation for saturation pressure is:

$$
P_{\text {sat }}=610.78 \times 10^{\left(\frac{7.5 T_{c}}{T_{c}+237.3}\right)}
$$

where $T_{c}$ is in degrees Celsius. Although this formulation is optimised for $0-100^{\circ} \mathrm{C}$, it is sufficiently accurate for $-5^{\circ} \mathrm{C}$.

The form of Sutherland's Law used for the dynamic viscosity of air is:

$$
\mu_{\text {air }}=18.27 \times 10^{-6}\left(\frac{291.15+120.0}{T+120.0}\right)\left(\frac{T}{291.15}\right)^{1.5}
$$

\section{Appendix 3: Leakage Model}

Here a simple control volume mixing analysis approach following that developed by Yoon et al. will be described with reference to Fig. 15 . 
If $f_{s}$ is the fraction of the mass flow leaking under the stator hub-shroud then, assuming incompressible flow, the axial velocity at the stator exit is:

$$
v_{x, \text { withleakage }}=U \phi\left(1-f_{s}\right)
$$

The exit tangential velocity of the flow through the stator is:

$$
v_{\theta 3, \text { withleakage }}=U \phi\left(1-f_{s}\right) \tan \alpha_{3}
$$

If the stator hub-shroud leakage re-enters with zero tangential velocity, then the total " $\dot{m} v_{\theta} "$ downstream of the stator is:

$$
" \dot{m} v_{\theta} "=\left(1-f_{s}\right) \dot{m} \times U \phi\left(1-f_{s}\right) \tan \alpha_{3}
$$

However, if $f_{r}$ is the fraction of mass flow passing over the rotor tip-shroud, then the " $\dot{m} v_{\theta} "$ that passes over the tip is:

$$
f_{r} \dot{m} \times U \phi\left(1-f_{s}\right) \tan \alpha_{3}
$$

Thus the " $\dot{m} v_{\theta} "$ that enters the rotor passage is:

$$
" \dot{m} v_{\theta} "=\left(1-f_{s}-f_{r}\right) \dot{m} \times U \phi\left(1-f_{s}\right) \tan \alpha_{3}
$$

The axial velocity at the rotor exit is:

$$
v_{x, \text { withleakage }}=U \phi\left(1-f_{r}\right)
$$

so the exit tangential velocity of the flow through the rotor is:

$$
v_{\theta 4, \text { withleakage }}=U \phi\left(1-f_{r}\right) \tan \alpha_{4}^{\text {rel }}+U
$$

Assuming that the stator hub-shroud leakage re-enters the mainstream with zero tangential velocity then the " $\dot{m} v_{\theta} "$ that leaves the rotor passage is:

$$
" \dot{m} v_{\theta} "=\left(1-f_{r}\right) \dot{m} \times\left(U \phi\left(1-f_{r}\right) \tan \alpha_{4}^{\text {rel }}+U\right)
$$

Combining Eqns (A3.5) and (A3.8) yields

$$
\Delta h_{0} / U^{2}=\left(1-f_{s}-f_{r}\right) \phi\left(1-f_{s}\right) \tan \alpha_{3}-\left(1-f_{r}\right)\left(\phi\left(1-f_{r}\right) \tan \alpha_{4}^{r e l}+1\right)
$$

Assuming that $f_{s}=f_{r}=f$ is small, then:

$$
\Delta h_{0} / U^{2}=\phi\left(\tan \alpha_{3}-\tan \alpha_{4}^{\text {rel }}\right)-1-f\left[\phi\left(3 \tan \alpha_{3}-2 \tan \alpha_{4}^{\text {rel }}\right)-1\right]
$$




\section{Tables}

Table 1: Effect of ambient variations on the turbine work compared to dry-air on a standard day (all at design flow coefficient and Reynolds number).

\begin{tabular}{|l|c|}
\hline & Work Change \\
\hline Non-dimensional blade speed $\pm 3 \%$ & $\pm 0.17 \%$ \\
\hline $2 \%$ absolute humidity $\left(c_{v} / R \quad 3.5\right.$ to 3.51$)$ & $+0.01 \%$ \\
\hline$+10 \mathrm{~K}$ causing $0.15 \%$ gap/span closure & $+0.71 \%$ \\
\hline Ignoring change in $R$ affecting bellmouth & $+0.45 \%$ \\
\hline
\end{tabular}

Table 2: Aerodynamic design parameters of LP turbine.

\begin{tabular}{|l|c|}
\hline Number of stages & 2 \\
\hline Mean radius & $0.6477 \mathrm{~m}$ \\
\hline Hub to tip ratio & 0.7 \\
\hline Design flow coefficient (both stages) & 0.822 \\
\hline Design Reynolds number & 148700 \\
\hline Design stage reaction (both stages) & 0.52 \\
\hline Design stage loading (both stages) & 2.02 \\
\hline Nominal blade Mach number & 0.076 \\
\hline Nominal non-dimensional blade speed & 0.0485 \\
\hline Nominal rotational speed & $379 \mathrm{rpm}^{3}$ \\
\hline Nominal volumetric flow rate & $19.7 \mathrm{~m}^{3} \mathrm{~s}^{-1}$ \\
\hline Number of blades: stator, rotor (both stages) & 84,112 \\
\hline Stator exit flow angle (mid-span) & $61.12^{\circ}$ \\
\hline Rotor exit relative flow angle (mid-span) & $-61.75^{\circ}$ \\
\hline Stator axial chord (mid-span) & $50 \mathrm{~mm}$ \\
\hline Rotor axial chord (mid-span) & $35 \mathrm{~mm}$ \\
\hline
\end{tabular}

Table 3: Fractional noise for a one-second sample.

\begin{tabular}{|l|c|}
\hline & Fractional noise $(\sigma / \mu)_{\text {Isec }}$ \\
\hline Flow coefficient, $\phi$ & $0.05 \%$ (repeatable) \\
\hline Reynolds number, $R e$ & $0.04 \%$ (repeatable) \\
\hline Turbine work coefficient, $\psi$ & $0.08 \%$ (not repeatable) \\
\hline Total-to-total efficiency, $\eta_{t t}$ & $0.10 \%$ (not repeatable) \\
\hline
\end{tabular}

Table 4: Fractional noise in the flow coefficient and Reynolds number for the baseline experiments.

\begin{tabular}{|l|c|c|}
\hline & $\phi$ & $\operatorname{Re}$ \\
\hline Observed $(\sigma / \mu)$ for $N=600$ & $0.0014 \%$ & $0.0011 \%$ \\
\hline Estimated $(\sigma / \mu)$ for $N=600$ & $0.0020 \%$ & $0.0016 \%$ \\
\hline
\end{tabular}

Table 5: Values used for humid air model.

\begin{tabular}{|c|c|c|}
\hline & water vapour & air \\
\hline Molar mass, $M$ & $18.0153 \mathrm{~kg} \mathrm{kmol}^{-1}$ & $28.9645 \mathrm{~kg} \mathrm{kmol}^{-1}$ \\
\hline
\end{tabular}


\begin{tabular}{|l|l|l|} 
Gas constant, $R$ & $461.522 \mathrm{~J} \mathrm{~kg}^{-1} \mathrm{~K}^{-1}$ & $287.057 \mathrm{~J} \mathrm{~kg}^{-1} \mathrm{~K}^{-1}$ \\
\hline
\end{tabular}

Table 6: Comparison of the model and the best-fit sensitivities of the turbine work coefficient and the resultant variation for the Baseline experiments.

\begin{tabular}{|c|c|c|c|c|c|}
\hline & & \multicolumn{2}{|c|}{ Model } & \multicolumn{2}{c|}{ Best-Fit } \\
\hline & Range & Sensitivity & Variation & Sensitivity & Variation \\
\hline$b$ & $1.01 \times 10^{-3}$ & 4.46 & $0.11 \%$ & 4.15 & $0.10 \%$ \\
\hline$g$ & $4.83 \times 10^{-4}$ & 0.042 & $0.001 \%$ & -4.45 & $0.05 \%$ \\
\hline$c$ & $5.26 \times 10^{-4}$ & -9.64 & $0.13 \%$ & -6.78 & $0.09 \%$ \\
\hline
\end{tabular}

Table 7: The range and fractional noise of the unaccounted and accounted turbine work coefficient using the model and the best-fit approaches.

\begin{tabular}{|c|c|c|c|c|}
\hline & \multicolumn{2}{|c|}{$\begin{array}{c}\text { Peak-to-peak } \\
\left(\psi_{\max }-\psi_{\min }\right) / \bar{\psi}\end{array}$} & \multicolumn{2}{c|}{$\begin{array}{r}\text { Fractional noise } \\
\left(\sigma_{\psi} / \bar{\psi}\right)\end{array}$} \\
\hline & Actual & Relative & Actual & Relative \\
\hline $\begin{array}{c}\text { Measured } \\
\text { unaccounted }\end{array}$ & $0.196 \%$ & $100 \%$ & $0.060 \%$ & $100 \%$ \\
\hline $\begin{array}{c}\text { Model } \\
\text { sensitivity }\end{array}$ & $0.069 \%$ & $35 \%$ & $0.023 \%$ & $38 \%$ \\
\hline $\begin{array}{c}\text { Best-Fit } \\
\text { sensitivity }\end{array}$ & $0.063 \%$ & $32 \%$ & $0.018 \%$ & $30 \%$ \\
\hline
\end{tabular}

Table 5: Values used for humid air model.

\begin{tabular}{|c|c|c|}
\hline & water vapour & air \\
\hline Molar mass, $M$ & $18.0153 \mathrm{~kg} \mathrm{kmol}^{-1}$ & $28.9645 \mathrm{~kg} \mathrm{kmol}^{-1}$ \\
\hline Gas constant, $R$ & $461.522 \mathrm{~J} \mathrm{~kg}^{-1} \mathrm{~K}^{-1}$ & $287.057 \mathrm{~J} \mathrm{~kg}^{-1} \mathrm{~K}^{-1}$ \\
\hline
\end{tabular}




\section{Figures}

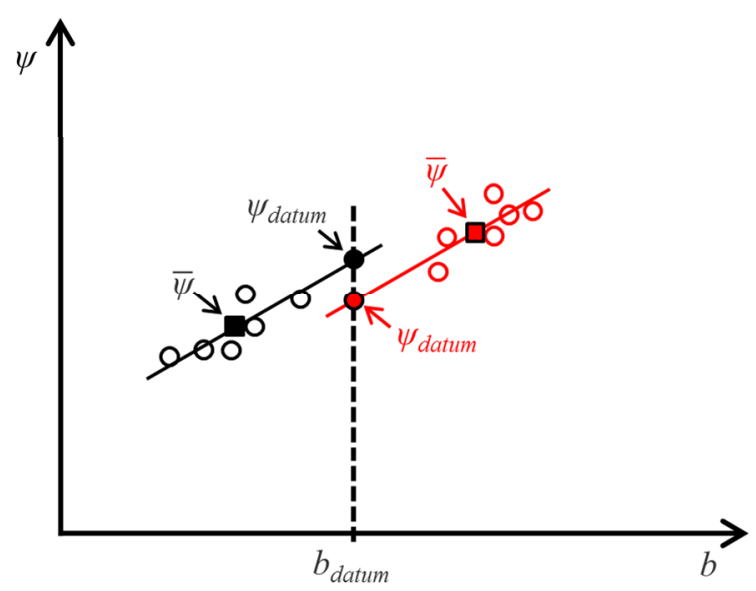

Fig.1: Illustration of how an uncontrolled variation in the non-dimensional quantity, $b$, can affect the turbine work coefficient, $\psi$. The mean values, $\bar{\psi}$, of the two data families gives an incorrect result. By accounting to a common $b_{\text {datum }}$, the $\psi_{\text {datum }}$ values yield a reliable result. 


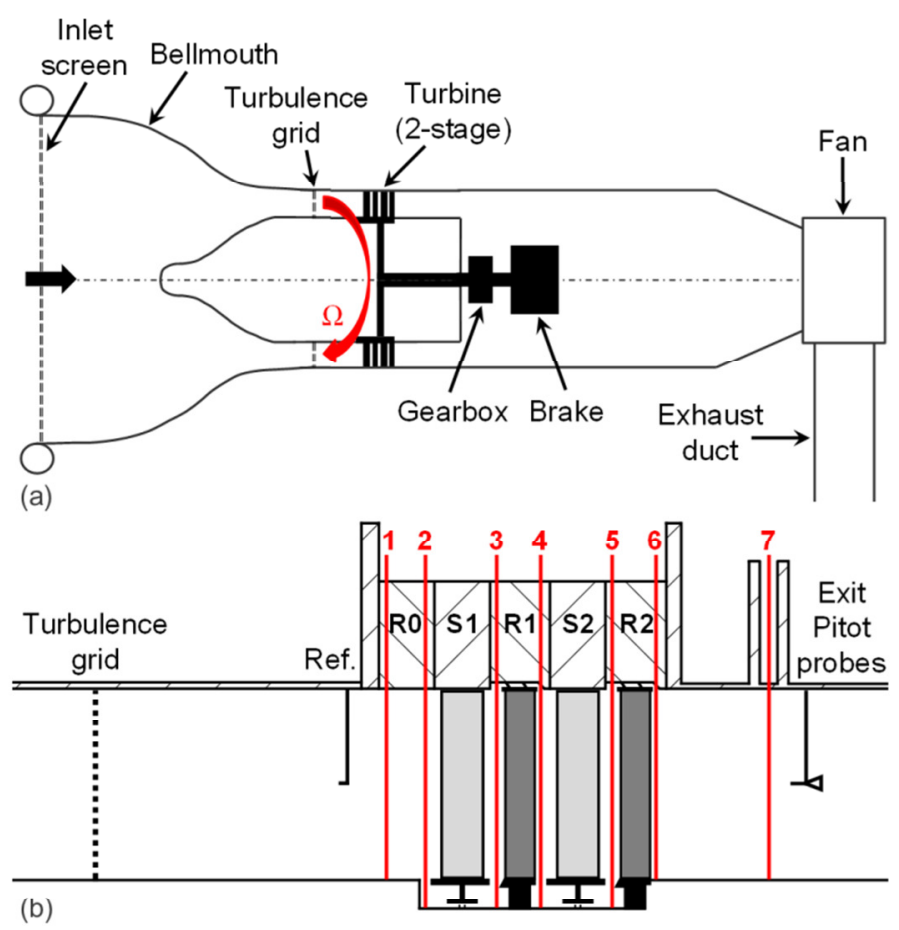

(c)

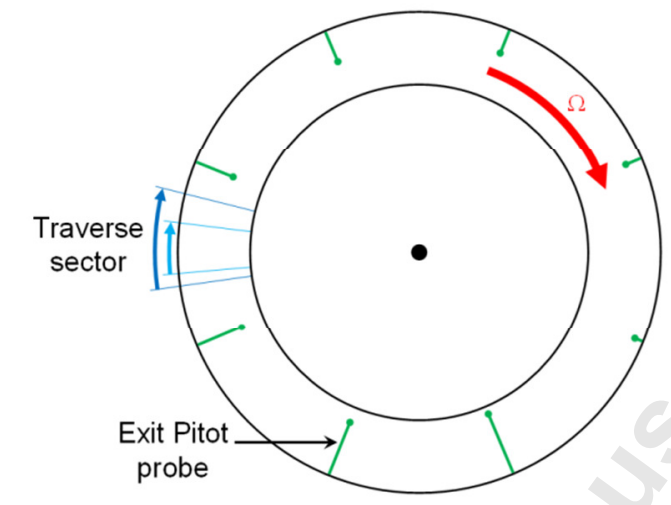

Fig. 2: Diagrams of the experimental facility: (a) schematic overview, (b) the working section (meridional view) and (c) circumferential positions of instrumentation (downstream view).

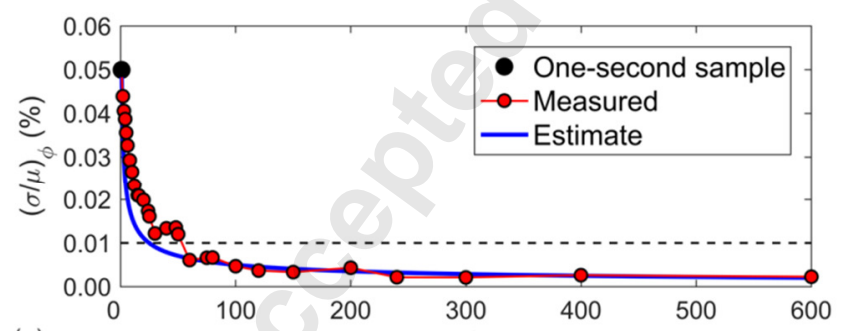

(a)

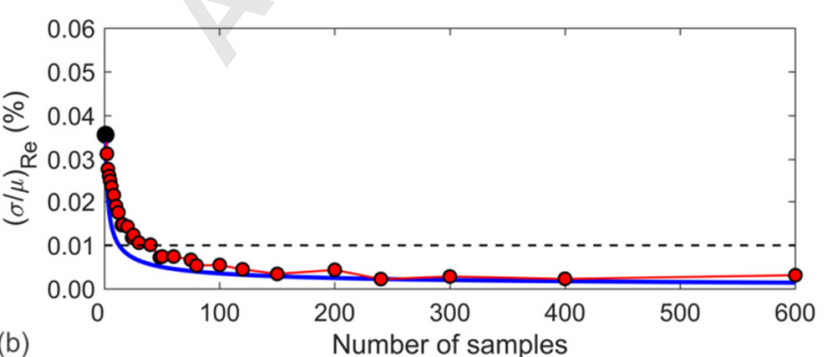

TURBO-16-1222 EVANS 33/39 
Fig. 3: Reduction of the fractional noise in (a) flow coefficient and (b) Reynolds number, estimated assuming independent data and experimentally verified using multiple measurements.
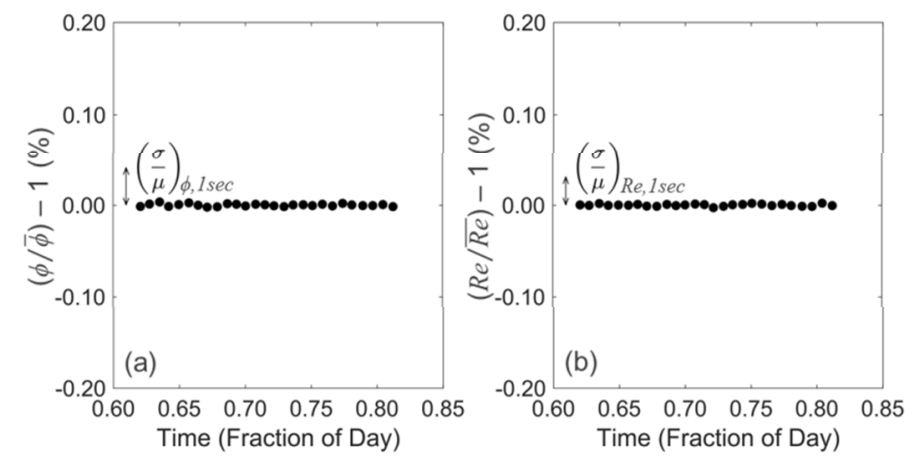

Fig. 4: Fractional variation of (a) flow coefficient (b) Reynolds number for the baseline experiments.

Each experiment involves 600 one-second samples.

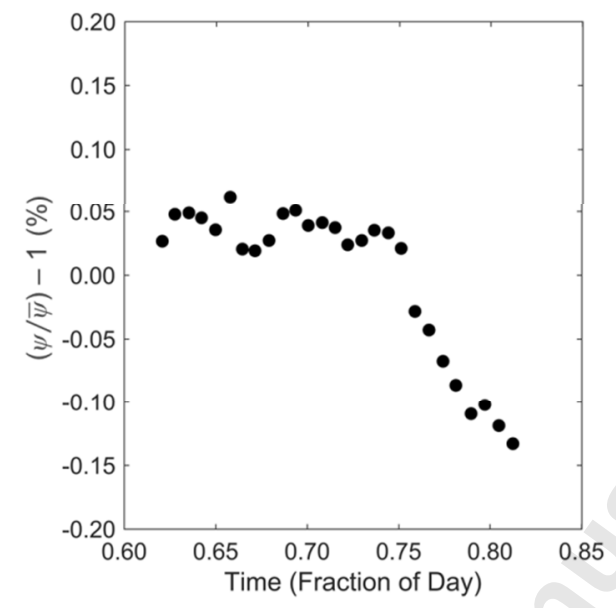

Fig. 5: Variation of the measured turbine work coefficient for the baseline experiments (design $\phi$ and $R e)$. Each experiment involves 600 one-second samples. 


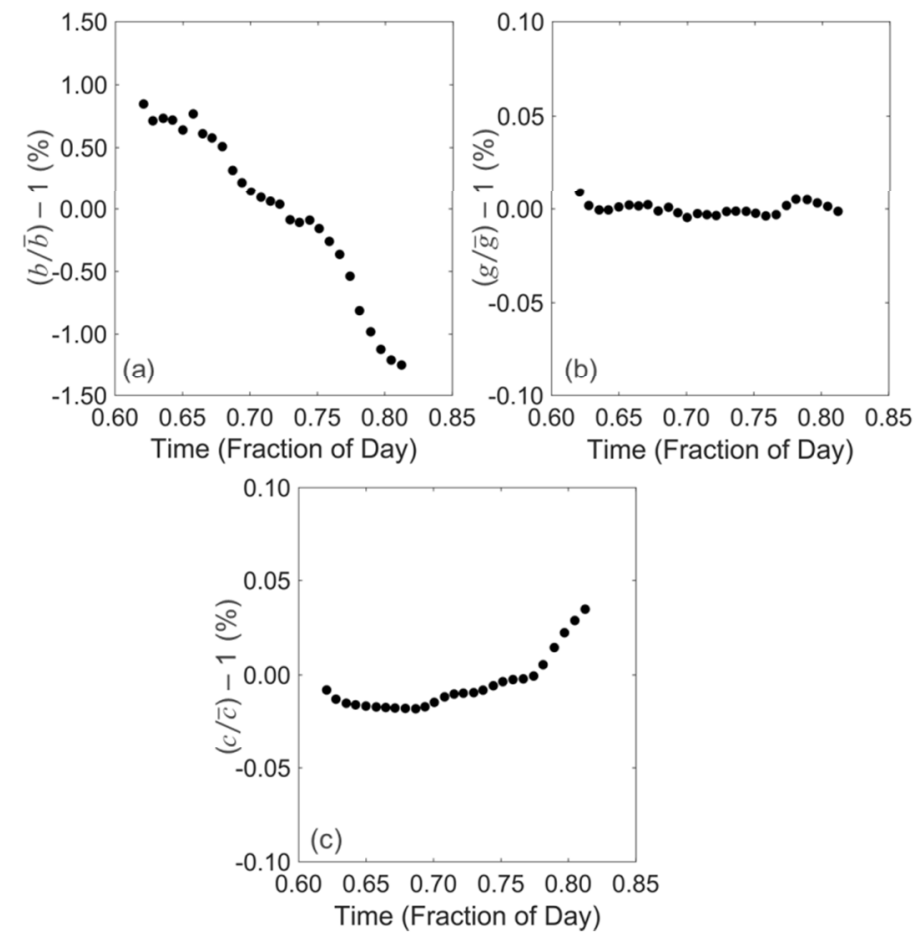

Fig. 6: Variation of the mean value of quantities during baseline experiments: (a) non-dimensional blade speed, (b) non-dimensional gas expansion and (c) non-dimensional clearance.
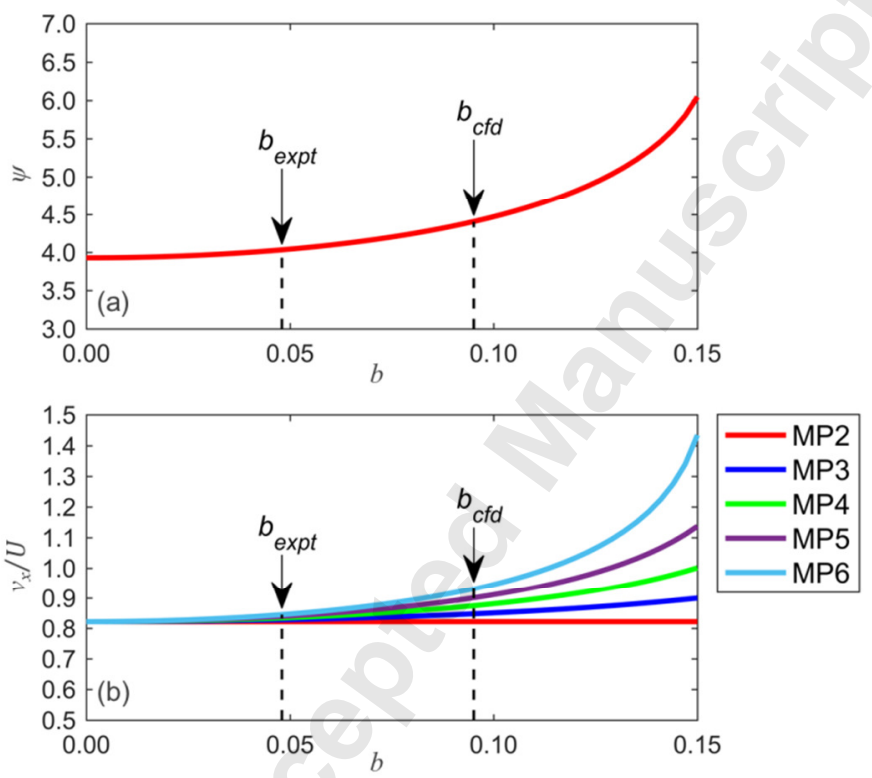

Fig. 7: For the two-stage configuration, the effect of non-dimensional blade speed on (a) the turbine work coefficient and (b) the axial velocities. 


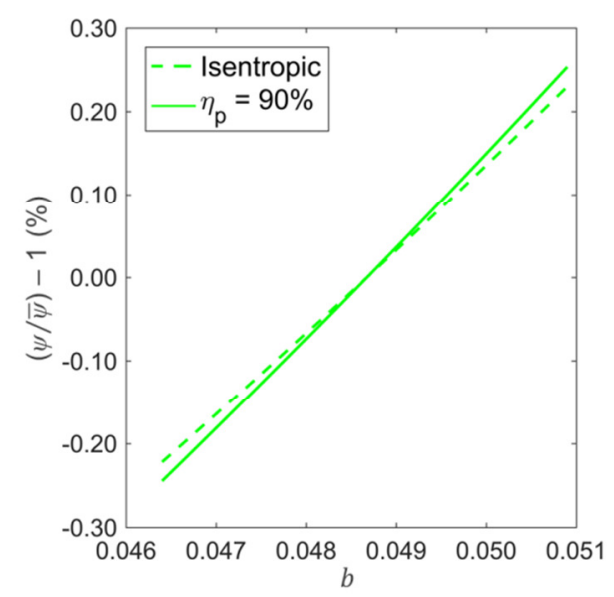

Fig. 8: The fractional variation of the turbine work coefficient calculated for the range of nondimensional blade speed during the experimental programme.

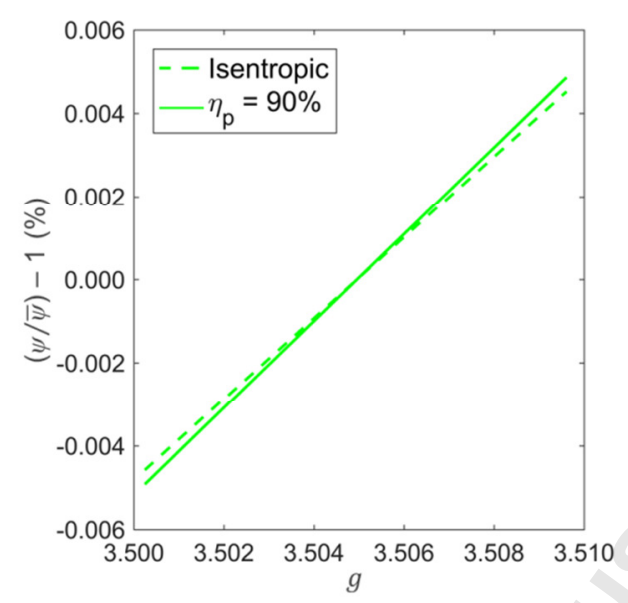

Fig. 9: The fractional change of the turbine work coefficient calculated for the range of nondimensional gas expansion during the experimental programme.

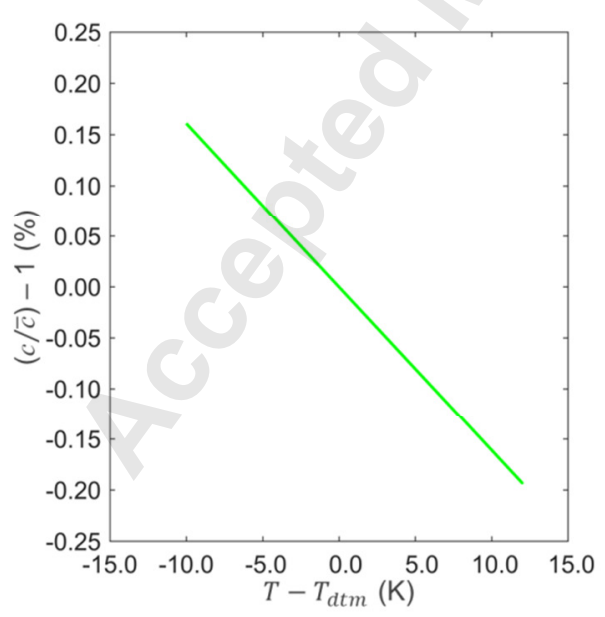

Fig. 10: The variation in $c=g a p /$ span for the range of facility temperature during the experimental programme. 


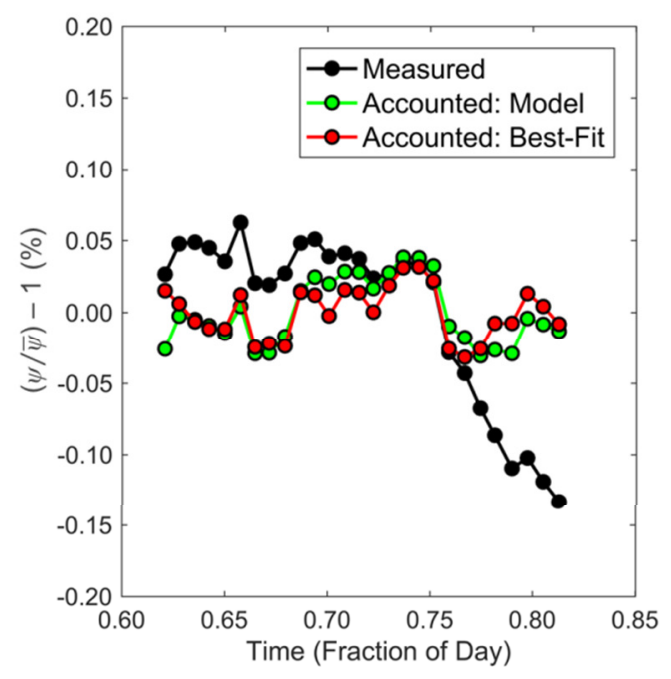

Fig. 11: Comparison of the measured unaccounted turbine work coefficient with the accounted values using the model and best-fit sensitivities.

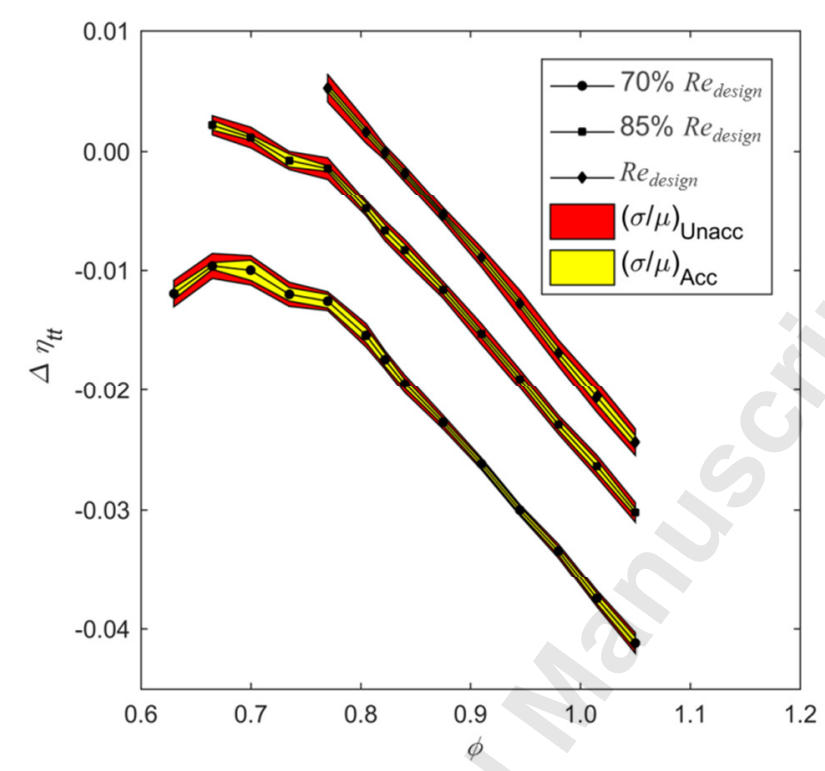

Fig. 12: Measured and accounted variation of total-to-total efficiency with flow coefficient and Reynolds number; red $=$ unaccounted, yellow $=$ accounted 

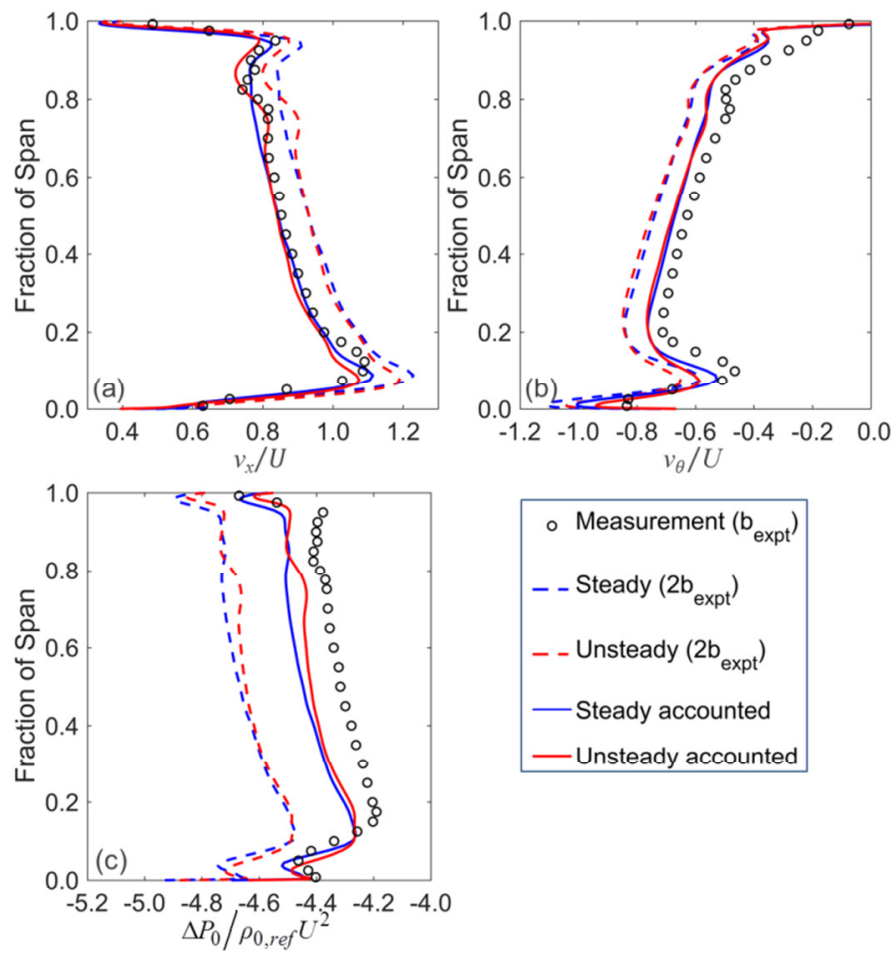

$$
\begin{aligned}
& \text { - Measurement }\left(\mathrm{b}_{\text {expt }}\right) \\
& - \text { - Steady }\left(2 \mathrm{~b}_{\text {expt }}\right) \\
& - \text { - Unsteady }\left(2 \mathrm{~b}_{\text {expt }}\right) \\
& \text { — Steady accounted } \\
& \text { — Unsteady accounted }
\end{aligned}
$$

Fig. 13: Spanwise profiles from the CFD calculations at double the experimental non-dimensional blade speed compared with accounted profiles and measurements.

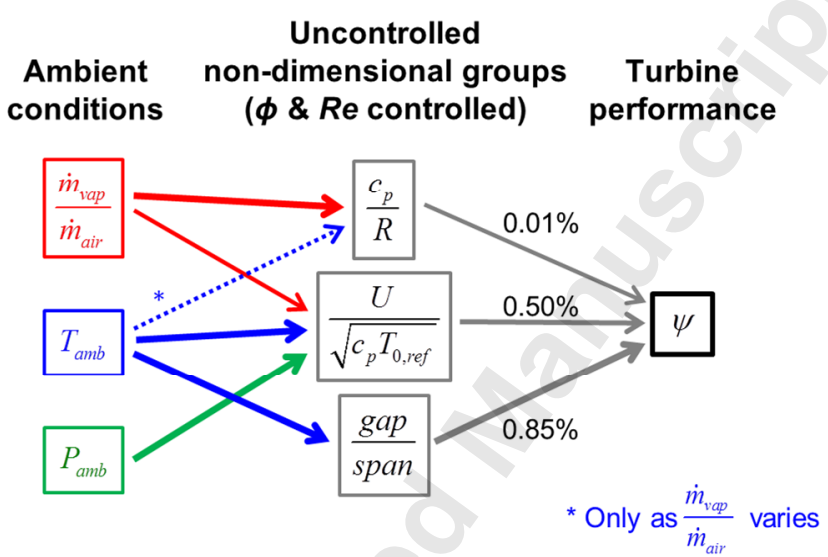

Fig. 14: Diagram showing the effect of the ambient conditions on the uncontrolled non-dimensional quantities and the size of the effect on the turbine work coefficient during the experimental programme. 

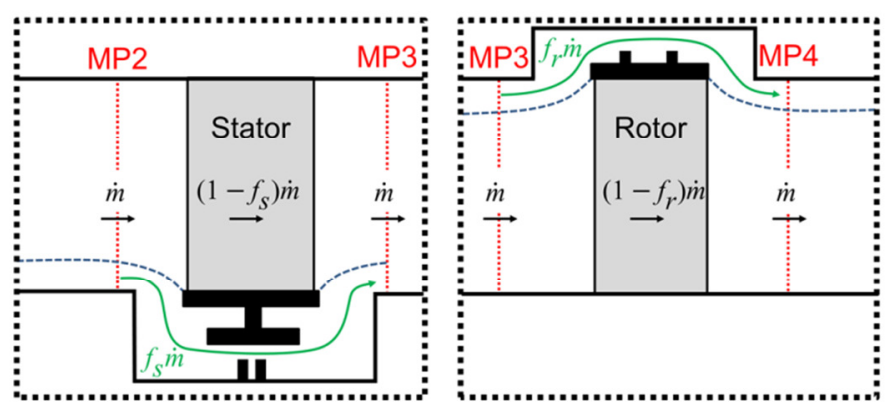

Fig. 15: Control volume analysis to estimate the effect of gap/span on turbine performance. 